\title{
A erosão da ideia de autoria
}

\section{Heloisa Buarque de Hollanda}

Professora emérita de Teoria Crítica da Cultura/Escola de Comunicação e coordenadora do Programa Avançado de Cultura Contemporânea/Faculdade de Letras, ambos da Universidade Federal do Rio de Janeiro. Desenvolve o projeto Universidade das Quebradas, baseado no conceito de ecologia dos saberes. Atualmente, as questões relativas ao cruzamento da tecnologia, cultura e desenvolvimento são seu foco principal.

E-mail: heloisa.buarque@gmail.com
Resumo: Este artigo refere-se às novas práticas identitárias e autorais no ambiente www; como essas práticas modificam a criação e a produção off-line. Pretende perpassar a questão do compartilhamento de conteúdos e dos papéis desempenhados pelo autor, pela produção de conhecimento e pela criação de conteúdo virtual.

Palavras-chaves: Ambiente virtual; Copyright; Copyleft; Creative commons; Cultura digital.

\section{Title: The erosion of the idea of authorship}

Abstract: This article refers to the new identity and copyright practices in www environment; how these practices modify the creation and offline production. It intends to pervade the issue of creative commons and roles of author, the production of knowledge, and the creation of virtual content.

Keywords: Virtual environments; Copyright; Copyleft; Creative common; Digital culture. 
Curiosamente, o tema a teatralidade do humano - ainda que na maioria das vezes refira-se a práticas artísticas e comportamentais que atravessam a História - encontra um terreno fértil nas práticas artísticas e comunitárias da web. Aqui, ela vem em diálogo direto e intenso com as novas práticas identitárias e autorais no ambiente "www" e seu reflexo na criação "off-line". Não fosse assim, a cultura do século XXI não seria tão profundamente marcada pela abertura de um debate radical acerca da questão da autoria.

Voltando um pouco no tempo, é interessante lembrar que o surgimento da noção de autoria, tal como a experimentamos hoje, vem mais ou menos sincronizada com a ascensão do individualismo e da economia de mercado pósRevolução Francesa. É nesse momento que surgem as primeiras leis reguladoras da propriedade intelectual, como a inglesa "copyright" e a francesa "droit d'auteur". Ainda que com pequenas distinções, ambas geraram um debate forte que já naquela época reforçava os dois eixos do problema: o direito do indivíduo vs. o interesse público. O direito do autor - bem como a importância da autoriaé, portanto, um direito relativamente novo, que surge gerando polêmicas e cuja origem sinaliza conflitos de base.

Por volta dos anos 1960/70, o debate cultural coloca em pauta outra questão não menos polêmica, também fruto dos novos paradigmas modelados pela revolução burguesa: a questão da centralidade do "sujeito". Em todas as áreas da cultura, as noções de sujeito e subjetividade são discutidas, testadas, experimentadas. É o noveau roman, o cinema de autor, a volta do figurativismo, a filosofia pósestruturalista. A morte do sujeito é proclamada como definitiva e incorpora-se à descoberta do "outro" e da "alteridade" como traço distintivo das rebeliões culturais dos anos 1960.

Em 1969, Michel Foucault traz esse debate para a noção de autor com o ensaio tão belo quanto fundamental, Qu'est un auteur? (FOUCAULT, 1969, p. 789821). Nesse trabalho, Foucault desloca a ideia essencialista da existência real de uma autoria para a noção de "função do autor". Ou seja, a autoria é uma noção construída historicamente e existe apenas em sua funcionalidade cultural e comercial. Desde então, a História parece ter se acelerado. Novos modelos políticos e culturais associados ao rápido desenvolvimento das tecnologias digitais emergem a cada dia, marcando o final do século XX como um momento de mudança paradigmática radical. Considerando apenas essa área, chamo atenção para a criação de equipamentos leves e de baixo custo, que oferece a todos a possibilidade de tornarem-se produtores culturais e divulgadores de conteúdo; e para o surgimento da internet, que inaugura a comunicação e a divulgação descentralizada e rápida, introduzindo formas inéditas de comunicação entre pessoas e comunidades. Isso sem falar nos equipamentos de comunicação móvel, que trazem surpresas e definem inovações decisivas na criação e no consumo culturais. Consolida-se o que chamamos de Geração $C$, ou a geração produtora de conteúdos que, pela facilidade atual de produção e difusão digitais, passa a ter um valor em si.

Ao lado da febre do conteúdo, essa mesma geração apresenta uma infinita possibilidade de atuação por meio de máscaras, nas quais se evidencia a questão da teatralidade exercida em grande escala nessas múltiplas teias permitidas pela web, que demonstrando sua capacidade de autorrepresentação e de articulação imediata vem afetando os modelos comportamentais vigentes.

Tentando resistir à tentação de mergulhar nessas águas, aqui vou procurar focar, dentre as tantas novidades que a virada do milênio nos trouxe, na questão das novas formas de criação e produção que indiciam um declínio da primazia do "autor" e o avanço de uma experimentação intensa em torno da criação compartilhada; dos formatos coletivos; das trocas produtivas e de uma complexa e polêmica positivação da "pirataria", por meio de práticas estéticas do cut and 
paste, do remix, do cover e das performances identitárias permitidas por vários novos programas, como por exemplo o Second Life, o My Space, com seus avatares e simulações, ou os grupos de comunidades virtuais, como Facebook, blogs e similares. Nesse campo, fica evidente a relativização das práticas autorais tradicionais. Os exemplos são infinitos e as audácias são favorecidas ao lado de uma legislação razoavelmente limitada, denunciando a complexidade de regulação que o universo "www" oferece. Entretanto, no mundo off-line as coisas também começam a sinalizar mudanças. Os movimentos culturais de vanguarda também começam a defender novas posições diante da hegemonia autoral e a defender o "plágio criativo".

Não foi por acaso que o movimento copyleft (a guerrilha comandada por artistas e escritores contra o copyright) expandiu-se de tal forma e com tal força que vários países já adotaram o modelo de regulamentação de direitos autorais, conhecido como creative commons, para responder a esse momento no qual já não é tão certo que os direitos do autor são patrimônio inexpugnável. Essa nova forma de legislação traz um espectro flexível de proteções para artistas e escritores. (LEMOS, 2005, p. 181-187)

O creative commons, representado no Brasil por Ronaldo Lemos, constitui, sem dúvida, um real avanço no lidar com a lei do copyright em tempos de abertura de espaço para reivindicações como o direito de acesso ao conhecimento e do livre exercício da cultura de troca. O creative commons, resumidamente, é uma busca de flexibilização dos direitos autorais, que passam a ser definidos pelo autor de determinada obra em função de sua decisão pessoal quanto à liberação ou não desses direitos ou parte deles para o uso público. As consultas ao creative commons são oferecidas num um site gratuito onde há vários tipos de licenças de uso para obras. Há licenças como "domínio público", "uso não comercial", "recombinação", "some rights reserved" e muitas outras. Essas inovações, tanto no campo prático quanto no jurídico, procuram enfrentar e superar os impasses das novas formas de produção, geralmente vistas, de forma simplista, como mera pirataria, enfatizando o sentido de uma fábrica cultural com poder de criação e cooperação social.

Ao lado dessas novas práticas há ainda a mídia tática, que propõe a reutilização das mídias tradicionais como TV, radio, vídeo, websites, impressos e os demais tipos de mídia eletrônica para dar voz a comunidades alternativas, dissidentes políticos e artistas de rua. Tanto o copyleft quanto a mídia tática prometem efeitos radicalmente transformadores não apenas do ponto de vista legal, que por si só é fascinante, mas principalmente como desafios aos modelos culturais vigentes, baseados quase completamente em ideias de autoria e autenticidade.

Na web, a evidência da experimentação da criação cultural compartilhada ou não-autoral é múltipla e quase a norma. Assim o comprovam os casos do Recombo, pioneiro na criação livre compartilhada, do Mídia Sana, que atropela a mídia oficial com ácidos remixes e tantos outros. Fora da web, pode-se observar como praticamente todas as áreas da criação vêm desenvolvendo alguma forma de fragilização da autoria como princípio criativo.

Nesse quadro, identidade, autoria, "raiz" e até mesmo subjetividade são noções que hoje se afirmam mais como fatores de negociação do que de essencialidades ou verdades. Trago aqui apenas um exemplo que me pareceu tão eloquente quanto representativo: o caso da atuação dos recentes coletivos de artistas plásticos. Os coletivos começam a surgir no final dos anos 1990 e realizam um trabalho de intervenção no espaço urbano. Politicamente, trazem em seu perfil traços do hip hop brasileiro que trocaram, com inegável sucesso e resultado, a posição reativa que marca as políticas defensivas de resistência dos anos 1960/70, ou mesmo a estratégia contracultural de atuar fora do sistema em ações de caráter proativo, ou seja, de enfrentar e tentar resolver de forma autônoma as dificuldades e carências 
de suas comunidades por meio de ações de efeito transformador imediato ou de médio prazo (MARTINS, 2005).

De forma similar, as intervenções dos coletivos de arte, também imbuídas do lead "o importante é agir", começam a assumir função política de denúncia social, agora em vias e praças públicas. Simultaneamente, esses trabalhos discutem a própria estrutura da produção nos moldes do circuito e do mercado de arte. Os coletivos, que se propagam em proporção geométrica pelo Brasil, trazem um diferencial de novidade. Os coletivos não se configuram por seus integrantes, mas sim por determinadas ações sempre em contextos de intervenção pública. Os coletivos também não são cooperativas, não são grupos, não têm número de participantes determinado nem podem ser caracterizados como movimentos artísticos. Sua forma de organização é independente e, para cada ação ou conjunto de ações, os coletivos buscam patrocínio, oferecendo cursos, vendendo trabalhos ou realizando serviços como ilustração, design, vídeo etc. Essa autogestão elimina, portanto, a figura do curador, personagem cujo poder seletivo e decisório cresceu muito nos últimos 20 anos, adquirindo uma função de autoridade centralizadora no sistema das artes. Contrariamente a essa tendência, a forma de organização dos coletivos é rizomática e nômade, o que marca sua diferença no campo das artes. Os coletivos são formados apenas em função da produção de um ou mais projetos. Estruturam-se para aquele fim específico e em seguida se recompõem com novos participantes em função de outro projeto. Isso quer dizer que a composição de um coletivo não é fixa, é móvel. Um artista pode pertencer a um coletivo em função de um projeto e no projeto seguinte juntar-se a outro coletivo para a realização de outro projeto.

A comunicação organizacional entre os coletivos é feita de forma bastante intensa por meio de blogs e listas de discussão na internet. Alguns sites reúnem as informações de forma mais articulada, explicitando melhor a lógica de rede que rege essa produção. Nesse sentido, existem, por exemplo, o site redecoro (s.d.) blog comunitário com informação sobre os sites -, ou ainda a rede dos teóricos de arte no site artesquema (s.d.). Portanto, os coletivos são organizações autogeridas, descentralizadas, flexíveis e situacionais; essa é a sua grande novidade. Nas autodefinições dos coletivos, percebe-se uma sintomática recorrência a citações de Antonio Negri em termos das noções de "multidão", de "trabalho-afeto" e "vida-arte". Essa forma de produção e agrupamento vem sendo típica do trabalho dos artistas visuais jovens, e, mais precisamente, de trabalhos de arte pública de natureza crítica e social. Diferenciam-se dos grupos ou cooperativas de produção, frequentes nos anos 1970, por serem estruturalmente nômades, unirem-se apenas em função de projetos tópicos e caracterizerem-se pela reunião em torno de ações concretas e imediatas, rejeitando a ideia de projetos em longo ou médio prazos. Segundo os integrantes de alguns coletivos, estes surgiram não por desejo, mas por necessidade; "o urgente é o real".

Um bom exemplo é a ação Ocupação na Ocupação. Durante três semanas de dezembro de 2003, 120 artistas realizaram uma intervenção no Edifício Prestes Maia, no Centro, em São Paulo, que estava ocupado por 470 famílias do Movimento dos Sem-Teto (MSTC). Nessa ação, que levou a sigla ACMSTC (Arte Contemporânea no Movimento dos Sem-Teto do Centro), os artistas realizaram trabalhos em colaboração com os ocupantes, promovendo uma grande interação entre os artistas e os integrantes do MSTC e dando um sentido de desagravo à intervenção.

É o que se conhece como a explosão do "Artevismo", um híbrido de arte + ativismo. Ou como eles mesmo denominam de "Arrivismo": "[...] s. m. Procedimento de arrivista, de quem quer vencer na vida de qualquer modo." (TAVARES, 2003). Essa priorização da ação transformadora nos remete à estética do rap, do grafite e da literatura marginal, abordados anteriormente e cuja forma de fazer política é priorizar a ação imediata e a divulgação agressiva da informação. 
Em outubro de 2003, foram publicados, numa pequena brochura, os Anais (LIMA; TAVARES, 2003) do primeiro congresso internacional de $\operatorname{Ar}(r)$ ivismo. Essa publicação traz algumas definições interessantes do projeto artístico e político dos coletivos. Na leitura dos Anais, percebe-se a forte presença de alguns termos e noções recuperados das décadas anteriores e agora ressemantizados. As recorrências mais frequentes ao longo destes Anais são as ideias de guerrilha cultural e da aproximação arte/vida como prioridades estratégicas. Revisitando um pouco a função dessas noções nos discursos dos anos 1960/70, conseguimos entender melhor as novas propostas da arte atualmente. Não entrando muito no sentido mais profundo do uso original das noções, eu diria que a ideia de guerrilha na década de 1960 implicava uma causa política e se manifestava por meio de um impulso utópico bastante forte. Hoje, a tática da guerrilha é usada de forma mais imediata e estratégica. A guerrilha, ou a intervenção que surpreende, é utilizada basicamente para se fazer ouvir ou para ser coberto pela mídia que passa a ser vista como um novo suporte possível para a obra de arte, com a vantagem de ter um caráter multiplicador.

Quanto à articulação direta entre arte/ vida, não é mais dirigida para a busca de uma indistinção entre o modo de viver e o modo de produzir arte ou literatura, como as produções alternativas dos anos 1970 , momento no qual a ideia de viver artisticamente e de criar de forma vitalista se manifestava a partir de uma exemplaridade contracultural.

Hoje, a aproximação entre a vida e a arte é entendida de forma diversa. A ligação arte/vida torna-se funcional enquanto forma de levar a arte para o cotidiano das ruas e agrupar os indivíduos-espectadores em torno de uma intervenção em seus hábitos. Portanto, essa ideia de levar a arte para a cena pública do cotidiano caracteriza-se explicitamente pela tática de ação, em vez de pelo estilo de vida ou visão da arte, como nos anos 1970. É ainda importante chamar a atenção para o fato de que a produção de um coletivo não valoriza a produção artística individual. $O$ autor da obra é o coletivo, e não o artista $x$, y ou z. Um minimanifesto assinado por Tulio Tavares, integrante do coletivo A Nova Pasta, composto de apenas um artista: "A(r)tivismo é brincadeira?/ O Ar(r)ivismo é sério?/ Com quantos umbigos se faz um grupo?/ Um(b)iguismo?" (TAVARES, 2003, p. 12)

O fato da criação desse coletivo de apenas um participante não é apenas um lance de humor ou nonsense. A ideia implícita na criação do coletivo é a interpelação do aqui referido como o Um(b)iguismo, e que eu traduziria pelo individualismo e pela necessidade da autenticidade da autoria que estrutura o mercado de arte. $\mathrm{E}$ com isso chegamos a um ponto central da atuação dos coletivos: a interpelação não apenas do sistema das artes, mas da lógica mais ampla da produção cultural em um de seus pontos mais sensíveis, que consiste na questão da autoria e da propriedade intelectual.

Num momento em que o software livre e a inclusão digital são discutidos nos fórum industriais e sociais, com a bandeira "conhecimento bom é conhecimento compartilhado", o campo da produção artística anuncia a irreversibilidade desse processo.

\section{Referências Bibliográficas}

ARTESQUEMA. Página inicial. Disponível em: <http://www.artesquema.com/ about/>. Acesso em: 07 maio 2013.

FOUCAULT, M. Qu'est-ce qu'un auteur? In: Dits et Écrits I. Paris: Gallimard, 1969. p. 789-821. 
LEMOS, R. Creative commons, mídia e as transformações recentes do direito da propriedade intelectual. Revista Direito GV 1, v. 1, n. 1, p. 181-187, maio, 2005.

LIMA, D.; TAVARES, T. (Eds.). I Congresso Internacional de Ar(r)ivismo, 2003. Anais... Disponível em: <http://tuliotavares.files.wordpress.com/2008/07/anais. pdf>. Acesso em: 19 abr. 2013.

MARTINS, R. Hip-Hop. O estilo que ninguém segura. São Paulo: Esetec, 2005.

REDECORO. redecoro. Disponível em: <http://redecoro.zip.net/>. Acesso em: 07 maio 2013.

TAVARES, T. I Congresso Internacional de Ar(r)ivistas - C.I.A. In: LIMA, D.; TAVARES,

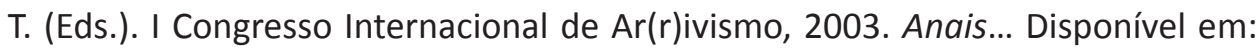
<http://tuliotavares.files.wordpress.com/2008/07/anais.pdf>. Acesso em: 19 abr. 2013. 